\title{
Information accessibility as an important global factor in accessible tourism
}

\author{
Jana Stuchlikova, ${ }^{1, *}$, and Milena Botlikova $^{1}$ \\ ${ }^{1}$ Silesian University in Opava, Faculty of Philosophy and Science, Institute of Spa, Gastronomy and \\ Tourism, Masarykova 343/37, 74601 Opava, Czech Republic
}

\begin{abstract}
Research background: The modern tourism industry has undergone many significant changes in recent years, from the increasingly massive use of modern technologies, through the negative effects of the COVID-19 pandemic, to a new trend in the form of increasing domestic tourism. If the tourism businesses wants to succeed in a competitive environment, they should focus on the quality of the information they publish on their websites, social networks or through other sources with greater intensity than before. Information accessibility is an important factor on the basis of which potential clients decide on the purchase of a tourist product. Until now, companies focused primarily on foreign clients now have more room to focus on the much-neglected issue of accessibility for clients with specific needs; on the other hand, companies focused on domestic clients can also expand the range language versions of their information channels. In addition, the fact that the accessibility of tourism businesses not only brings a competitive advantage, but also strengthens the economic potential of the region.

Purpose of the article: The aim of the paper is to map the level of information accessibility of tourism companies, primarily gastronomic facilities in the Czech Republic.

Methods: Primary data obtained from controlled interviews with representatives of professional associations and operators of monitored facilities and secondary data from publicly available sources were used.

Findings \& Value added: The paper contains model examples of the state of information accessibility in tourism companies.
\end{abstract}

Keywords: Information accessibility; accessible tourism; competitive advantage

JEL Classification: $A 19 ; M 31 ; Z 33$

\footnotetext{
${ }^{*}$ Corresponding author: jana.stuchlikova@,fpf.slu.cz
} 


\section{Introduction}

Tourism is considered to be a sector that has a significant impact on a number of other areas around the world, in particular on economic, environmental and social aspects. And it is the social aspects related to the increasing importance of corporate social responsibility, which is relevant not only in tourism but also in other sectors, which subsequently brought with it the emergence and development of tourism for all and social and accessible tourism. Tourism for all seeks to create accessible tourist destinations and products and takes measures to enable travel and full use of tourism services for all groups of potential customers, regardless of their economic situation, while respecting their uniqueness and individuality. Social tourism includes all initiatives that make tourism accessible to people with special needs, especially low-income people. The aim of accessible tourism is to remove or suppress obstacles that complicate travel for certain groups of customers or discourage them from participating in tourism. Accessibility expresses the possibility for all visitors to have easy access to facilities, buildings, transport, information, communication, attractions and other services, to actively participate in programs and events for guests and to benefit from them (ISO, 2021). Staff competencies play an important role, namely the ability to respond to specific customer needs (ENAT, 2021).

Accessible tourism seeks to enable all people, regardless of age and health, to travel and participate in community life. The trend of population aging is a factor to which organizations and companies, including those operating in the field of tourism, are trying to adapt their offer, as well as to families with children and, last but not least, to people with disabilities. The fact is, especially due to the financial demands of the measure, that it is very difficult to remove barriers and adapt the environment for the latter segment (Kazuist, 2017).

In recent years, various initiatives have been taken to improve the accessibility of tourism in a large number of countries. One of the areas worked was the inclusion and accessibility of information for all, especially for people with disabilities and other users with digitalfocused access needs, given the growing importance of the Internet in everyday life. Individual countries should apply the relevant standards, both in accordance with their own regulations and those of the UN agreements on access to information on online tourism, in order to promote more sustainable tourism (Gonzales et al., 2020).

For more than one billion people in the world who live with some kind of disability, traveling can be a daunting task. The International Organization for Standardization (ISO) considers it important to remove unnecessary barriers to tourism; Tourism and related services - Accessible tourism for all - Requirements and recommendations, The standard provides requirements and guidelines to ensure that people of all ages and abilities have equal access to and use of tourism. This includes anyone who might face accessibility problems or have specific access requirements, such as people with disabilities and the elderly. In 2021 and 2022, UNWTO, Fundación ONCE and UNE, together with experts, will run an awareness campaign aimed at their members and collaborators in order to emphasize the harmonization of accessible tourism worldwide through standards. (ENAT, 2021)

\section{Methodology}

The aim of the paper is to map the level of information accessibility within accessible tourism in general and to describe more specifically the situation in the Czech Republic, including tools to improve the availability of information. Comparative analysis and own survey were used (for more see 3.2), while primary data were obtained from controlled interviews with representatives of professional associations and operators of tourism enterprises. Secondary data were obtained from publicly available sources. 


\section{Results}

The key finding was that commercial information on accessibility in tourism is often unreliable, leading to a number of actors mapping it in recent years (see below), with different methodologies not being uniform as they arose independently of each other. The main reason for the situation was the fact that service providers usually do not have accurate information about the basic principles of accessibility, ie. what specific measures to implement (Abraham et al., 2019). The current level of barrier-free and information accessibility in the Czech Republic is relatively low, which is mainly due to the inadequacy of information on the accessibility of tourism services. Although some tourism service providers provide information on accessibility (websites, printed materials, etc.) as part of promotional activities, this information often does not correspond to reality. However, the consumer finds out the real situation only after arrival on the spot and is thus exposed to a number of unpleasant, sometimes unsolvable situations, which in some cases completely prevents him from moving around the building and the surrounding environment and therefore does not allow full consumption of services. E.g. The community of people in wheelchairs uses modern technology to transfer information to each other and evaluate the accessibility of buildings and the environment through the mobile application Vozejkmap, where the personal experiences of people in wheelchairs are located. The value of information from guaranteed databases is very high for consumers in this environment of uncertainty, in order to ensure the permanence of information by regularly updating these databases by their operators. Another problem is the unpreparedness of staff towards clients with specific communication needs.

The following subchapter summarizes the essential information that approaches the issue of accessibility in tourism, including related legal standards and institutions not only in general, but also on specific examples.

\subsection{Accessibility in tourism}

The idea of accessibility in tourism is based on the philosophy of "universal design", which the International Center for Universal Design defines as "product and environment design, applicable to all people, as much as possible, without the need for modification or specialized design." (Burgstahler, 2017).

Globally, many authors consider "universal design to be a paradigm that extends the concept of continuous paths, accessibility and mobility and a barrier-free environment, including the inclusion of intergenerational planning that recognizes the link between aging, disability and people's evolving skills throughout their lives". (Darsy et al., 2010).

The UNWTO Secretary-General emphasized that accessible tourism should be at the heart of any responsible and sustainable tourism policy: "it is both a necessary human right and an expanding business opportunity. Above all, we must realize that barrier-free travel is not only beneficial for people with disabilities or special needs, but also for us all. " (UNWTO, 2021).

Among the authors who deal with this issue most intensively are Buhalis and Darcy (2011), who define accessible tourism as "tourism involving and requiring the cooperation of all stakeholders. The result of this collaboration is a universally designed tourism product, service and environment that enables people with specific accessibility requirements, including mobility, sight, hearing and cognitive functions, to participate independently on equal and dignified tourism. "Stakeholders are people with permanent or temporary disabilities, seniors, obese people or families with small children and also providers of tourism services, who thus work in a safer and more socially favorably managed and 
maintained environment. The above view takes into account a lifelong approach to clients who can benefit from accessible tourism measures throughout their lives.

A potential client with specific needs expects the accessibility of a comprehensive offer, across the entire chain of tourist services in the destination. Accessibility of services is formed by dimensions see table no. 1:

Table 1. Dimensions of service accessibility.

\begin{tabular}{|c|c|}
\hline Type of accessibility & Examples of use in practice \\
\hline Physical accessibility & $\begin{array}{l}\text { accessibility of buildings and the environment, transport, } \\
\text { infrastructure }\end{array}$ \\
\hline Information accessibility & $\begin{array}{l}\text { reliability of information, accessible communication } \\
\text { channels, standards for accessibility assessment }\end{array}$ \\
\hline Communication accessibility & $\begin{array}{l}\text { behavior of staff towards clients and the way of } \\
\text { communication with them }\end{array}$ \\
\hline Economic accessibility & choice of different price levels \\
\hline
\end{tabular}

Source: Own processing according to ENAT (2021)

Segments of clients with special needs include in particular: seniors (people over 65), people with disabilities, people accompanying children under three, pregnant women, people with acute injuries preventing movement, people with chronic diseases, people with internal organ diseases, small or oversized people, people with bulky luggage, etc.

\subsubsection{Legal norms in the field of accessibility}

There are regulations on the accessibility of websites and mobile applications at both EU and national levels, which use the harmonized standard EN 301549 V2. 1.2 (2018-08) referring to internationally recognized standards, in particular the Web Content Accessibility Guidelines (WCAG) 2.1. Act 99/2019 Coll. Is also in force in the Czech Republic. on the accessibility of websites and mobile applications, which has been updated in order to make the acquisition of information or the provision of various areas of life accessible to blind people, of whom more than 80,000 live here. But because these technologies facilitate faster orientation and access to information, they also serve users who have no health restrictions, such as the elderly (Porto et al., 2019).

Directive (EU) 2016/2102 of the European Parliament and of the Council on the accessibility of websites and mobile applications of public sector bodies sets out, inter alia, the reasons for complying with legislative procedures, in particular: The trend towards a digital society provides users with new ways of accessing information and services. Providers of information and services, including public sector bodies, are increasingly using the Internet to create, collect and provide a wide range of online information and services that are essential to the public. Furthermore, the Directive of the European Parliament and of the Council on accessibility requirements for products and services has been in force since 17 April 2019. The content of this directive includes the definition of persons with health insurance in accordance with the 2011 UN Convention, which has been ratified by all EU states. This directive has benefited other people with disabilities, such as the elderly, pregnant women, travelers with luggage and more (Postma and Papp, 2021).

The European Union has issued a directive on the accessibility of websites and mobile applications, which aims to make these technologies accessible to public sector bodies across the European Union, based on standards and common accessibility requirements (Vila et al., 2020). 
The first international standard for accessible tourism, ISO 21902: 2021, was newly published this year (see above for more details). Furthermore, building laws that address the accessibility of buildings, minimum numbers of barrier-free rooms in accommodation facilities, sanitary facilities in catering establishments or public buildings and more cannot be neglected. Barrier-free use of buildings is stipulated in decrees concerning general technical requirements.

\subsubsection{Entities operating in the field of accessibility}

Below are the key entities that have an impact on the development of accessibility of buildings and environments with international scope, and especially those that are active in the Czech Republic.

DPI - Disabled Peoples 'International, a non-profit company founded in 1981, is headquartered in Ottawa, Canada and operates in 139 countries through its member national assemblies (MNAs). Since 1983, the DPI has also had a special advisory status with the United Nations Economic and Social Council (UN ECOSOC). It is a global organization for people with disabilities.

ENAT - Europen Network for Accessible Tourism was established in January 2006 as a project initiative of nine sponsoring organizations in six EU Member States. Currently, it is a non-profit association for organizations whose goal is to become "pioneers" in the study, promotion and practice of accessible tourism. Using the knowledge and experience of the network, its members (almost 250) improve the accessibility of tourist information, transport, infrastructure, design and services for visitors with all types of access needs and provide models of excellence in accessible tourism for the entire tourism industry.

EDF - European Disability Forum is an independent NGO umbrella organization for people with disabilities, which defends the interests of more than 100 million people with disabilities in Europe.

TRIANON, z.s. - the company was established in 2003 and its mission is to contribute to the development of civil society through the activities of the pilot program Without Barriers - Without Borders ${ }^{\circledR}$ and the sustainable development of the border region of the Czech Republic, Poland and Slovakia. educational institutions, the non-profit sector and personalities. The target groups of the program are people with disabilities of working age, seniors and students. In TRIANON, sustainable development is perceived as the intersection of three basic pillars, ie economic-social-environmental. Promoting mobility and accessibility for all is one of the main goals of the association.

NRZP CR - The National Council of Persons with Disabilities was founded in 2000, currently has 112 member organizations that associate over 300,000 people with disabilities or their representatives. Since 11 December 2014, the NRZP ČR has been a registered association with nationwide competence, which represents the interests of persons with disabilities in negotiations with state and public institutions. The role of the NRZP CR is to contribute to the integration of people with disabilities into society and to consistently defend the human rights of these people. It fulfills this role by commenting on legislative norms and implementing projects that contribute to the integration of people with disabilities into society in all spheres of activity. It is the main advisory body of the Government Committee for Disabled Citizens and is also a member of four international organizations defending the interests of people with disabilities. These organizations are: European Disability Forum, Rehabilitation International, FIMITIC and Disabled Peoples 'International. Its priorities also include: coordinating the progress of organizations of people with disabilities in matters of common interest, informing the public about disability issues, monitoring cases of discrimination against people with disabilities, implementing projects to improve life with disabilities, planning opportunities for equal opportunities for people with disabilities. 
disability at the regional and regional level, operation of a nationwide network of counseling centers for professional social counseling, publishing publications, magazines and information materials.

NIPI barrier-free environment, o.p.s. - this organization started its activities in 2008, the founder of NIPI is the National Institute for the Integration of Persons with Reduced Mobility and Orientation of the Czech Republic, a.s. (official abbreviation NIPI CR, o.s.). The aim and purpose of NIPI ČR, o.s. is to support the functioning of modern civil society. Within this goal, NIPI $\check{C}$, o.s. interest to contribute through its activities, especially in the area of supporting the creation of an environment that can be freely used by all groups of the population, including groups that are at risk of social exclusion. Among the main activities of NIPI CR, o.s. These include support for the development of partnerships, methodological, professional and consultancy activities on the integration of persons with reduced mobility and compliance with United Nations standard rules. More than 50 NIPI consultants assess according to Decree 398/2009 Coll. and the new Building Act, the accessibility of any new or reconstructed equipment.

KAZUIST spol. s r. o. is a regional advisory information center, the scope of which is economic and legal advice for small and medium-sized enterprises, vocational training, implementation of projects to support business in the region and the implementation of projects to support the development of barrier-free tourism. It was founded in 1991 and is a member of ENAT of the European Association for Barrier-Free Tourism. The projects and activities of the Case Study in the field of barrier-free tourism (hereinafter CR) include, for example: Beskydy for All, Moravian-Silesian Region for All, Athena, Journeys of Discovery, etc., database www.jedemetaky.cz, which was created within the Tourism without barriers. Unfortunately, the company has not focused on accessibility for the third year in a row and is not updating the database www.jedemetaky.cz.

POV - The Prague Organization of Wheelchair Users was founded on the initiative of wheelchair users and their loved ones in 1991. Through its projects, work and attitude, it seeks to create a socially favorable environment in which everyone with disabilities can freely decide on their lives and how to provide their basic living conditions. needs. It provides services that are divided into three areas: information system, directories and client information support, Over Barriers program - a set of activities related to the removal and mapping of architectural barriers, educational and leisure events. A number of organizations and institutions in the Czech Republic, in cooperation with POV at various levels, are involved in mapping the accessibility of the environment from the point of view of people with reduced mobility. Most of them have regional scope, while some of them already use a unified system, which is based on the Methodology of categorization of accessibility of objects. The POV, with the support of the Ministry of Regional Development, also published the Methodology for Categorizing the Accessibility of Routes and Roads.

Atis Travel Agency offers clients with disabilities the product line Holiday with a wheelchair, which includes accommodation facilities in the Czech Republic, Slovakia and Hungary. The form with items related to accessibility is sent by CK Atis to the relevant hotels. The client will find the necessary information on the TA website and will assess whether the accommodation facility is suitable for him personally.

The Bezbatour travel agency is based in Prague and is a subsidiary of Pestré společnosti o. S. The original intention of this CA was to map accessibility for trained employees in selected accommodation facilities throughout the Czech Republic. However, CA withdrew from this intention and currently uses a similar methodology as CK Atis.

Due to the methodological procedures used, it is possible to consider the information of the above-mentioned subjects as guaranteed.

In connection with information accessibility, it is necessary to mention the Information Portal for People with Special Needs Helpnet.cz, which has been operating since 2003 and 
provides up-to-date information to target groups across the spectrum not only by type of specific needs but also by cross-cutting topics including legislation, counseling, education, services and more.

\subsection{Information accessibility as an important part of accessible tourism}

Information accessibility is an important factor on the basis of which potential clients decide on the purchase of a tourist product and is also one of the important criteria in accessible tourism (Gao et al., 2017). The first decade of the 21 st century saw fundamental and inspiring changes in European and global society regarding the understanding and acceptance of the value of human diversity. The international safeguarding of the human rights of people with disabilities in the form of the 2006 UN Convention on the Rights of Persons with Disabilities is just one aspect of a changing mentality. The principles of mutual respect and interdependence between people are becoming more and more apparent. The development of products, services, media and communication tools for the mass market also shows a shift towards personalization and individualized solutions based on an understanding of the fact that customers are characterized by very diverse tastes, preferences, lifestyles and requirements (Europen Network for Accessible Tourism, 2021).

At the same time, it is important to perceive visitors from different perspectives, whether in access to information, local transport, accommodation and visits to destinations (Kirilenko and Stepchenkova, 2018). The concept of an accessible tourism destination applied to a locality, region or county is therefore linked to the availability of facilities and accessible transport infrastructure, leading to a diverse, demanding and accessible environment (Kolodziejczak, 2019). In practice, for the purpose of developing concepts and strategies, they use surveys and comparisons of tourism accessibility measures, inter alia, through an objective set of metrics in the spirit and purpose of international treaties and missions on the rights of people with disabilities (Porto et al., 2019). Analyze the availability of destinations for the purpose of global recreational tourism management and the definition of precise routes with regard to the accessibility of the area, using aerial digital images in combination with mapping and analysis of the data obtained (Sing et al., 2021).

Accessible tourism as a huge market potential affects the entire tourism chain, including all tourism facilities from arrival, accommodation, restaurants, activities in holiday resorts to the departure process. In order to offer barrier-free tourism, two types of accessibility need to be considered. The accessibility of tourism extends the common object of tourism, especially with information concerning the requirements of disabled people (Michopoulou et al, 2016). Web accessibility is responsible for presenting the accessibility of tourism in a transparent and accessible way. To facilitate access, the existing tourism information systems support both tourism facility providers in adding additional information on accessibility to tourism facilities and tourists with disabilities in obtaining the required accessibility information (Winkler et al., 2006). When taking advantage of the digital environment, smart devices and sets of mobile and desktop applications for the support of tourism, which ensure the accessibility of information to all participants in tourism, cannot be neglected (Mandic and Pranicevic 2019). The tourism product must be designed for all people, regardless of age, gender and ability, as one of the requirements for complying with the concept of accessible travel. (Fryer, 2020).

Internet. The Internet played an important role in the development of tourism not only due to the possibility of fast and cheap dissemination of information, but a well-designed website has become a powerful marketing tool, which has had and still has an impact on the economic growth of companies (Karahuta et al., 2017). When looking at the functions and usability of the Internet, we must respect two perspectives, namely providers who promote their services, inform the client about destinations, products, prices, and clients who obtain 
information about the offer, prices, ratings, reviews, options via the Internet booking of accommodation, transport or other additional tourism services. Below are the most commonly used options used to obtain and transmit information when connected to the Internet.

The use of presentation or promotion through websites is a matter of course for entities active in the field of tourism. Therefore, more and more emphasis is placed on the content, updating of information, creation of product databases with the possibility of their reservation, flexibility and effectiveness of these supportive means of promotion or easy orientation in the structure of the site (Yochum et al., 2020).

Email, or e-mail, or generalized, is generalized to the name of electronic mail, which is a collection of all documents sent over the Internet.

The use of social networks in tourism was an inevitable step due to its popularity and the opportunities that these networks provide. On these pages you can share information, photos, videos and games, you can create pages with the possibility of presenting your own company, tourist facilities, information centers or cultural or sporting events.

Virtual tours are one of the key options for promoting a given locality for use in tourism. Undoubtedly the biggest advantage is the ability to view the object of interest before the visit. The emphasis is mainly on quality. Today's technologies also enable panoramic tours that can use a $360^{\circ}$ viewing angle. Some providers also add information about the location to the virtual tours, including maps, or the possibility of accommodation, transport and other services.

Google Earth is the best-known and most widely used application that allows users to view maps around the world via satellite imagery. Zooms in on terrain maps, threedimensional images of buildings and other objects, provides the ability to create routes. This application is very flexible in terms of end user settings and is very accurate and up to date.

An integral part of web technologies is the management of so-called blogs, where the authors update posts of various content and focus.

Webcams are a valuable source of information for users in tourism. They allow you to look into the real environment at a specific time. They are therefore an important source of information, whether in terms of weather, occupancy of swimming pools or water parks or the occupancy of mountain ski resorts.

Trip Advisor is one of the most widely used online tourism projects, allowing users to share information about locations, pictures, videos or reviews and advice from individual travelers. (Kaisešotová, 2019).

\subsection{Mapping the level of information accessibility in tourism companies in the Czech Republic}

We supplemented our own marketing research with surveys and analyzes carried out throughout the Czech Republic, eg by the Association of Hotels and Restaurants, Kazuist, etc. In addition to controlled interviews with representatives of professional associations and state institutions, we conducted a survey among operators of travel agencies, information centers, spas, accommodation and catering facilities, especially in the Moravian-Silesian Region in the period July - September 2021, 24 people were contacted.

The survey showed that all respondents found significant reserves in information accessibility and accessibility to the affected buildings, with the main reason as the absence of a comprehensive system of methodology, requirements and rules that individual entities could follow outside the building law. They stated that private entities mapping accessibility replace state institutions with their activities, in addition, these organizations lack financial support and usually find it very problematic to obtain funds from other private entities. 
The majority of respondents (93\%) stated that they see another problem in the lack of education not only for service providers but also for the general public, although objectively there have been improvements in recent years, partly due to the use of modern technologies, including the Internet. Surprising was the ignorance of the head of the state institution about the activities of private entities in the field of accessibility.

Regarding catering facilities in the Moravian-Silesian Region, 2\% of the monitored companies do not have established websites, but only social networks and $0,4 \%$ do not have their own websites and do not use social networks.

\section{Discussion and conclusions}

Despite all the above shortcomings, there has been a significant shift in the field of information accessibility, especially in recent years. This is due both to the increasing demand of today's clients and also the efforts of operators to satisfy a given group of customers and provide comprehensive and comprehensive information. Previously, information on the acceptance of different groups of customers or the provision of a given range of services was not visible. The client had to search for information, find out and usually turned directly to the organization, which meant large time and work demands on their employees.

At present, thanks to modern technologies, especially the Internet, it is possible to obtain and at least a basic set of information, such as what the service provider offers and for whom the service is intended. Ideally also in the form of pictograms, voice messages and other desirable forms. They are gradually being used mainly thanks to non-profit organizations of interest, but also thanks to legislative measures and the efforts of prestigious organizations in the field. For example, in the case of top-rated caterers, Michelin Guide, Maurer's Choice or TopLife's Top Restaurant, which awards golden lions, require individual restaurants to indicate in their questionnaires whether they are wheelchair accessible, accept dogs, and offer seating with a view. whether they are suitable for families with children. There are a number of monuments that have barrier-free entrances or descriptions in Braille, there are travel agencies on the market offering a holiday for wheelchair users, the Association of Hotels and Restaurants evaluating physical accessibility to establishments and more. However, in addition to the above, there is a need to focus more on training service staff to be able to communicate properly with clients with specific requirements and, last but not least, to provide them with up-to-date information in a comprehensible way.

\section{Acknowledgements}

The article was created within the project SGS1/2021 "Information accessibility of tourism in the segment of gastronomic facilities of the Moravian-Silesian region" at the Faculty of Philosophy and Science, Silesian University in Opava.

\section{References}

1. Abraham, R., Schneider, J. \& Vom Brocke, J. (2019). Data governance: a conceptual framework, structured review, and research agenda. International Journal of Information Management, 49, 424-438.

2. Buhalis, D. and Darcy, S. (Eds) (2011). Accessible Tourism: Concepts and Issues. Channel View Publications, Bristol. 
3. Burgstahler, S. (2017a). Universal Design of Instruction. University of Washington. Seattle.

4. Darcy, S., Cameron, B., \& Pegg, S. (2010) Accessible tourism and sustainability: a discussion and case study. Journal of Sustainable Tourism, 18(4), 515-537.

5. Europen Network for Accessible Tourism. (2021, August 29). Publication Of First International Standard On Accessible Tourism for All, Led by UNWTO, Fundación $O N C E$ and UNE. https://www.accessibletourism.org/?i=enat.en.news.2245

6. Fryer, L. (2020). Accessing access: the importance of pre-visit information to the attendance of people with sight loss at live audio described events. Universal Access in the Information Society.

7. Gao, J., Huang, Z. W., \& Zhang, C. Z. (2017) Tourists' perceptions of responsibility: an application of norm-activation theory. Journal of Sustainable Tourism, 25(2), 276-291.

8. ISO-International Organization for Standardization. (2021, September 21). Tourism and related services. https://www.iso.org/standard/72126.html

9. Kaisersotova, L. (2021, September 26). Informační a rezervační systémy cestovního ruchu. VOVCR. https://www.vovcr.cz/odz/ekon/418/page00.html

10. Kirilenko A. P., \& Stepchenkova S. (2018). Tourism research from its inception to present day: Subject area, geography, and gender distributions. PLoS ONE, 13(11), Article e0206820.

11. Karahuta, M., Gallo, P., Matusikova, D., Senkova, A., \& Sambronska, K. (2017). Forecast of Using Neutral Networks in the Tourism Sektor. CBU International Conference on Innovations in Science and Education, 218-223.

12. Kolodziejczak, A. (2019). Information as a Factor of the Development of Accessible Tourism for People with Disabilities. Quaestiones GeographicaeI, 38(2), 67-73.

13. Mandic, A., \& Pranicevic, D.G. (2019). Progress on the role of ICTs in establishing destination appeal Implications for smart tourism destination development. Journal of Hospitality and Tourism Technology, 10(4), 791-813.

14. Michopoulou E., Darcy S., Ambrose I., \& Buhalis D. (2016). Accessible tourism futures: The world we dream to live in and opportunities we hope to have. Journal of Tourism Futures, 1(13), 179-188.

15. Pražská organizace vozíčkářru. (2021, October 4). https://www.presbariery.cz/cz/mapovani-barierovosti/mapujici-organizace-a-instituce

16. Porto, N., Rucci, C. A., Simon, D., Garbroro, N., \& Almond, B. (2019). Critical elements in accessible tourism for destination competitiveness and comparison: Principal component analysis from Oceania and South America. Tourism Management, 75, 169 185.

17. Postma, A., \& Papp, B. (2021). Of trends and trend pyramids. Journal of Tourism Future, 7(2), 162-167.

18. Singh, R., Ismail, A., PS, S. \& Singh, D. (2021). Compliance of accessibility in tourism websites: a pledge towards disability. Journal of Hospitality and Tourism, 4(3), 263-281.

19. Vila, T. D., Gonzalez, E. A., \& Darcy, S. (2020). Accessibility of tourism websites: the level of countries' commitment. Universal Access in the Information Society, 19(2), 331346.

20. Yochum, P., Chang, L., Gu, T. \& Zhu, M. (2020). Linked Open Data in Location-Based Recommendation System on Tourism Domain: A Survey. In IEEE Access, 8, 1640916439. 